\title{
Association of glucose variability with postoperative delirium in acute aortic dissection patients: an observational study
}

\section{Yanjuan Lin ( $\sim$ fjxhyjl@163.com )}

Fujian Medical University Union Hospital https://orcid.org/0000-0003-0368-4893

Ling-Yu Lin

Fujian Medical University School of Nursing

\section{Yan-Chun Peng}

Xiehe Affiliated Hospital of Fujian Medical University

Hao-Ruo Zhang

Fujian Medical University

\section{Liang-wan Chen}

Xiehe Affiliated Hospital of Fujian Medical University

\section{Xi-Zhen Huang}

Xiehe Affiliated Hospital of Fujian Medical University

\section{Qiong Chen}

Fujian Medical University School of Nursing

\section{Research article}

Keywords: glucose variability, postoperative delirium, acute aortic dissection patients

Posted Date: April 21st, 2020

DOl: https://doi.org/10.21203/rs.3.rs-18296/v1

License: (9) This work is licensed under a Creative Commons Attribution 4.0 International License. Read Full License 


\section{Abstract \\ Background}

Blood glucose variability is associated with poor prognosis after cardiac surgery, but the relationship between glucose variability and postoperative delirium in patients with acute aortic dissection is unclear. The aim of this study is to investigate the association of blood glucose variability with postoperative delirium in acute aortic dissection patients.

\section{Methods}

We prospectively analyzed 257 patients including 103 patients with delirium. The patients was categorized into two groups according to whether delirium was present. The outcome measures were postoperative delirium, the length of Intensive Care Unit stay and the duration of hospital stay. Multivariable Cox competing risk survival models was used to assess.

\section{Results}

A total of 257 subjects were enrolled, including 103 patients with delirium. There were statistically significant differences between the two groups in age, body mass index, first admission blood glucose, white blood cell counts, Acute Physiology and Chronic Health Evaluation II score, hypoxemia, mechanical ventilation duration and the length of Intensive Care Unit stay $(P<0.05)$. The median of mean of blood glucose and standard deviation of blood glucose were higher in the delirium group than in the nondelirium group, and the difference was statistically significant $(P<0.05)$. In model 1 , the adjusted hazard ratio of standard deviation of blood glucose was $1.436(P<0.05)$. In Model 2, the SDBG (AHR $=1.418$, $95 \% \mathrm{Cl}=1.195-1.681, P<0.05)$ remained significant after adjusting for confounders $(P<0.05)$. The area under curve of the SDBG ROC was $0.763(95 \% \mathrm{Cl}=0.704-0.821, P<0.01)$. The sensitivity was $81.6 \%$, and the specificity was $57.8 \%$.

\section{Conclusions}

Glucose variability is associated with the risk of delirium in patients after aortic dissection surgery, and high glycemic variability increases the risk of postoperative delirium.

\section{Background}

Postoperative delirium (POD) is a severe cerebral dysfunction, and is characterized by episodes of confusion, inattention, thinking disorder and mental state change of mental state change. ${ }^{1}$ It is one of the neurological complications after cardiac surgery with the incidence of as high as $11.0 \%-54.9 \% .{ }^{2,3}$ And the 
incidence of delirium after aortic dissection surgery is $32.5 \%-52.0 \% .{ }^{4}$ Studies have shown that POD leads to prolonged mechanical ventilation, prolonged Intensive Care Unit (ICU )stay, a 20\% increased risk of long-term hospitalization for each day, the lasting delirium, and increased hospital costs. ${ }^{5-7}$ In addition, the patients' activity ability and quality of life are decreased. ${ }^{8}$

In recent years, more attention has been paid to the study of blood glucose variability (GV) on disease progression and prognosis of patients, and it has important clinical significance for monitoring and controlling of blood GV in severe patients. ${ }^{9,10}$ Compared with hyperglycemia, blood GV can better reflect changes in the condition and has greater adverse effects on the body, which may has higher clinical value. $^{10,11}$ It is well known that blood GV increases the risk of adverse events after cardiac surgery, such as acute kidney injury, and the risk of short-term and long-term death. ${ }^{12,13}$ At present, only one article has pointed out that hypoglycemia is positively correlated with delirium in mixed ICU diabetic patients, but high blood GV is not correlated with delirium. ${ }^{14}$ And there is no study on the correlation between POD and blood GV in patients after cardiac surgery, nor the effect of blood GV on POD after acute aortic dissection $(A A D)$.

According to reports, the annual incidence of $A D$ was $3.0-6.0$ per $100,000 .^{15}$ The mortality rate was $36-$ $72 \%$ in $A A D$ in the hospital during $48 \mathrm{~h}$, an increase of $1-2 \%$ in the hourly mortality rate. ${ }^{16}$ Surgery is an important way to AAD. Therefore, this study conducted an observational study to investigate the relationship between blood GV after postoperative aortic dissection and POD, and to further clarify whether blood GV has an effect on POD.

\section{Methods}

\section{The Aim And Design}

The study is to investigate the relationship between blood GV after postoperative aortic dissection and POD, and to further clarify whether blood GV has an effect on POD, which is an observational study

\section{Participants}

All patients who underwent AAD surgery at Fujian Heart Medical Center from June, 2017 to June, 2019. All patients were $\geq 18$ years old, no metabolic disease, no history of malignant tumor, autoimmune disease, or no severe liver and kidney dysfunction. Excluding those who stayed in ICU less than 48 hours after operation, a history of craniocranial trauma, congenital deafness or schizophrenia, epilepsy before surgery, and patients who had been using glucocorticoids for a long time. In addition, patients who remained in a coma in the ICU after the operation were also excluded. The Confusion Assessment Method for Intensive Care Unit (CAM-ICU) ${ }^{17}$ was used to assess whether the patient had positive delirium. 
The acute physiology and chronic health evaluation (APACHE-II) is the most authoritative critical illness evaluation system that has been widely used in ICU. The more serious the illness is, the higher the score is. Studies have shown that the severity of the disease is closely related to the risk of delirium ${ }^{18,19}$.

\section{Delirium Assessment}

Delirium was assessed by two ICU nurses who have been worked in the ICU for more than 3 years. Evaluation time was from 8:00 to 11:00, 15:00 to 17:00, and 20:00 to 23:00 on the first day after surgery, until delirium occurred or the patient transferred out of ICU.

The CAM-ICU scale can identify the following four characteristics: (1) acute onset of change or fluctuation in mental status; (2) attention disorder; (3) altered level of consciousness; (4) disorganised thinking. At the same time satisfy the features 1,2 , and 3 or 1,2 , and 4 can be diagnosis of positive delirium.

\section{Data Collection}

After the patient was transferred to the ICU, the general demographic data, intraoperative data, and postoperative data were collected by a single investigator. And the blood glucose level was collected at 8 am on the first day and continuously collected for 48 hours. The blood glucose value is obtained from the arterial blood gas analysis, If the interval between the two blood glucose was longer than 6 hours, the patient was excluded. Mean of blood glucose(MBG) is the average blood glucose value of 48 hours, and the variability of blood glucose was assessed by the standard deviation of blood glucose(SDBG).

\section{Statistical Analysis}

We used Excel (Microsoft Corporation, Redmond, WA, USA) to calculate the SDBG and the MBG, and SPSS statistical package of 21.0 version to statistical analysis, using the appropriate statistical methods to describe data. The continuity variable conforms with the normal distribution uses the test and the non-compliance with the normal distribution uses the Wilcoxon signed rank sum test. The length of ICU stay was the time index, calculating in days. It started from the first day when patients stay in the ICU until the patient was treated as a truncated value. Multivariate Cox regression analysis was performed to determine whether delirium occurred as a dependent variable (event), and hazard ratio (HR) values and $95 \%$ confidence intervals $(\mathrm{Cl})$ were obtained. $P<0.05$ was considered statistically significant.

\section{Results}

From June 2017 to June 2019, 296 patients with AAD were included, and 257 patients were finally included, as shown in Fig. 1. There were 103 patients with delirium and 154 patients with non-delirium, and the incidence of delirium was $40.01 \%$. 
Table 1 shows demographic and clinical characteristics of delirium group and non-delirium group. There was no statistically significant difference in age between the two groups $(P>0.05)$. There were statistically significant differences between the two groups in body mass index (BMI), first admission blood glucose, white blood cell (WBC) count, APACHE-II score, hypoxemia, mechanical ventilation duration and the length of ICU stay $(P<0.05)$. The median of MBG and SDBG were higher in the delirium group than in the non-delirium group, and the differences were statistically significant $(P<0.05)$. 
Table 1

Characteristics of delirium patients and non-delirium patients

\begin{tabular}{|c|c|c|c|}
\hline Variables & $\begin{array}{l}\text { Delirium } \\
(n=103)\end{array}$ & $\begin{array}{l}\text { Without Delirium } \\
(n=154)\end{array}$ & $P$ \\
\hline \multicolumn{4}{|l|}{ General information } \\
\hline Age, mean (SD), years & $53.27(10.46)$ & $51.06(12.76)$ & 0.145 \\
\hline $\mathrm{BMI}$, median IQR, $\mathrm{kg} / \mathrm{m}^{2}$ & $\begin{array}{l}25.35(23.51 \\
27.68)\end{array}$ & $\begin{array}{l}24.00(22.20 \\
26.68)\end{array}$ & 0.014 \\
\hline Male & $81(78.6)$ & $113(73.4)$ & 0.336 \\
\hline Smoker & $41(39.8)$ & $60(39.0)$ & 0.892 \\
\hline Drinker & $41(39.8)$ & $56(36.4)$ & 0.577 \\
\hline High school and above & $20(19.4)$ & $36(23.4)$ & 0.374 \\
\hline Married & $100(97.1)$ & $152(98.7)$ & 0.648 \\
\hline Hypertension & $83(80.6)$ & $112(72.7)$ & 0.149 \\
\hline History of cardiac surgery, & $7(5.5)$ & $2(1.6)$ & 0.084 \\
\hline \multicolumn{4}{|l|}{ Preoperative data } \\
\hline First time blood glucose, IQR, mmol/L & $7.58(6.60,9.20)$ & $6.86(5.90,7.75)$ & $\begin{array}{l}< \\
0.001\end{array}$ \\
\hline WBC, mean (SD), $\left[\times 10^{9} / \mathrm{L}\right]$ & $12.91(4.11)$ & $11.82(3.91)$ & 0.033 \\
\hline Neutrophil, median (IQR), $\left[\times 10^{9} / \mathrm{L}\right]$ & $10.0(6.96,12.63)$ & $8.54(4.57,11.54)$ & 0.061 \\
\hline Lymphocyte, median (IQR), $\left[\times 10^{9} / \mathrm{L}\right]$ & $6.50(4.10,10.0)$ & $7.10(4.10,11.28)$ & 0.330 \\
\hline Monocyte, median (IQR), $\left[\times 10^{9} / \mathrm{L}\right]$ & $5.00(3.50,8.00)$ & $5.4(2.6,7.60)$ & 0.344 \\
\hline RBC, median (IQR), $\left[\times 10^{9} / \mathrm{L}\right]$ & $4.31(3.93,4.77)$ & $4.32(4.00,4.68)$ & 0.922 \\
\hline Platelet, median (IQR), $\left[\times 10^{9} / \mathrm{L}\right]$ & $\begin{array}{l}196.0(149.8 \\
235.0)\end{array}$ & $\begin{array}{l}193.0(149.75 \\
217.0)\end{array}$ & 0.138 \\
\hline $\mathrm{Hb}$, median (IQR), g/L & $\begin{array}{l}134.0(122.0 \\
146.0)\end{array}$ & $\begin{array}{l}\text { 131.0 (118.0, } \\
142.0)\end{array}$ & 0.175 \\
\hline
\end{tabular}

Values are $n(\%)$ unless otherwise indicated.

$\mathrm{BMI}=$ Body Mass Index; IQR = Interquartile; $\mathrm{WBC}=$ White Blood Cell; $\mathrm{RBC}=$ Red Blood Cell; $\mathrm{Hb}=$ hemoglobin; ASA = American Society of Anesthesiologists; CPB = Cardiopulmonary Bypass; APACHE = Acute Physiology and Chronic Health Evaluation Score; $\mathrm{MBG}=$ Mean of Blood Glucose; $\mathrm{SDBG}=$ Standard Deviation of Blood Glucose. 


\begin{tabular}{|c|c|c|c|}
\hline Variables & $\begin{array}{l}\text { Delirium } \\
(n=103)\end{array}$ & $\begin{array}{l}\text { Without Delirium } \\
(n=154)\end{array}$ & $P$ \\
\hline Anemia & $18(17.5)$ & $21(13.6)$ & 0.896 \\
\hline ASA grade & & & 0.608 \\
\hline III level & $20(19.4)$ & $24(22.1)$ & \\
\hline$\geq I V$ level & $83(80.6)$ & $120(77.9)$ & \\
\hline Entry status & & & 0.173 \\
\hline Quiet & $50(48.5)$ & $64(41.6)$ & \\
\hline nervous & $33(32.0)$ & $67(43.5)$ & \\
\hline confused & $20(19.4)$ & $23(14.9)$ & \\
\hline \multicolumn{4}{|l|}{ Intraoperative data } \\
\hline Operating time, median (IQR), minutes & $\begin{array}{l}299.0(255.0 \\
365.0)\end{array}$ & $\begin{array}{l}290.5(253.5 \\
362.5)\end{array}$ & 0.642 \\
\hline Aortic cross-clamp time, median (IQR), minutes & $65.0(46.0,95.0)$ & $57.0(43.0,95.0)$ & 0.326 \\
\hline CPB, median (IQR), minutes & $\begin{array}{l}155.0(130.0 \\
188.0)\end{array}$ & $\begin{array}{l}149.0(125.0 \\
186.5)\end{array}$ & 0.600 \\
\hline Blood loss, median (IQR), ml & $\begin{array}{l}800.0(600.0 \\
1000)\end{array}$ & $\begin{array}{l}800.0(600.0 \\
1000)\end{array}$ & 0.367 \\
\hline \multicolumn{4}{|l|}{ Postoperative data } \\
\hline APACHE-II scores & & & $\begin{array}{l}< \\
0.001\end{array}$ \\
\hline$<15$ & $38(36.9)$ & $111(72.1)$ & \\
\hline $15-20$ & $46(44.7)$ & $32(20.8)$ & \\
\hline$>20$ & $19(18.4)$ & $11(7.1)$ & \\
\hline Hypoxemia & $52(50.5)$ & $25(16.2)$ & $\begin{array}{l}< \\
0.001\end{array}$ \\
\hline MBG, mmol & $\begin{array}{l}13.07(11.6 \\
15.02)\end{array}$ & $10.68(9.56,11.91)$ & 0.001 \\
\hline
\end{tabular}

Values are $\mathrm{n}(\%)$ unless otherwise indicated.

$\mathrm{BMI}=$ Body Mass Index; IQR = Interquartile; $\mathrm{WBC}=$ White Blood Cell; $\mathrm{RBC}=$ Red Blood Cell; $\mathrm{Hb}=$ hemoglobin; ASA = American Society of Anesthesiologists; CPB = Cardiopulmonary Bypass; APACHE = Acute Physiology and Chronic Health Evaluation Score; $\mathrm{MBG}=$ Mean of Blood Glucose; $\mathrm{SDBG}=$ Standard Deviation of Blood Glucose. 


\begin{tabular}{|c|c|c|c|}
\hline Variables & $\begin{array}{l}\text { Delirium } \\
(n=103)\end{array}$ & $\begin{array}{l}\text { Without Delirium } \\
(n=154)\end{array}$ & $P$ \\
\hline SDBG, mmol & $2.90(2.18,3.87)$ & $1.73(1.26,2.54)$ & $<.001$ \\
\hline ICU stay, median (IQR), day & $7.0(5.0,10.0)$ & $5.0(4.0,7.0)$ & $\dot{0} 001$ \\
\hline $\begin{array}{l}\text { Mechanical ventilation duration, median (IQR), } \\
\text { hours }\end{array}$ & $61.0(37.0,139.0)$ & $42.5(27.8,82.3)$ & $<.001$ \\
\hline $\begin{array}{l}\text { Hospitalization days, } \\
\text { median (IQR), day }\end{array}$ & $21.0(15.0,26.0)$ & $18.0(14.0,25.0)$ & 0.357 \\
\hline \multicolumn{4}{|l|}{ Values are $\mathrm{n}(\%)$ unless otherwise indicated. } \\
\hline \multicolumn{4}{|c|}{$\begin{array}{l}\text { BMI = Body Mass Index; } \mathrm{IQR}=\text { Interquartile; WBC = White Blood Cell; } \mathrm{RBC}=\text { Red Blood Cell; } \mathrm{Hb}= \\
\text { hemoglobin; } \mathrm{ASA}=\text { American Society of Anesthesiologists; } \mathrm{CPB}=\text { Cardiopulmonary Bypass; APACHE } \\
\text { = Acute Physiology and Chronic Health Evaluation Score; MBG = Mean of Blood Glucose; SDBG = } \\
\text { Standard Deviation of Blood Glucose. }\end{array}$} \\
\hline
\end{tabular}

In Table 2, patients were divided into lower GV group and higher GV group according to the median of the SDBG. There were no statistically significant differences in age, BMI, gender, smoker, drinker, education level, marital status,hypertension and history of cardiac surgery, etc. Compared with the lower GV group, the length of ICU stay in the higher GV was longer, and the difference between the two groups was statistically significant $(P<0.05)$. 
Table 2

Baseline characteristics of patients with low and high GV

\begin{tabular}{|c|c|c|c|}
\hline \multirow[t]{2}{*}{ Variables } & Lower GV & Higher GV & \multirow[t]{2}{*}{$P$} \\
\hline & $N=129$ & $N=128$ & \\
\hline Age, mean (SD), years & $50.78 \pm 12.67$ & $53.12 \pm 11.04$ & 0.117 \\
\hline BMI, median IQR, kg/m² & $\begin{array}{l}24.75(22.78 \\
27.18)\end{array}$ & $24.22(22.50,26.72)$ & 0.575 \\
\hline Male & $97(75.2)$ & $97(75.8)$ & 0.913 \\
\hline Smoker & $52(40.3)$ & $45(35.2)$ & 0.394 \\
\hline Drinker & $53(41.1)$ & $48(37.5)$ & 0.556 \\
\hline High school and above & $31(24.0)$ & $25(19.5)$ & 0.190 \\
\hline Hypertension & $92(71.3)$ & $103(80.5)$ & 0.086 \\
\hline Married & $127(98.4)$ & $125(97.7)$ & 0.645 \\
\hline History of cardiac surgery & $2(1.6)$ & $7(5.5)$ & 0.088 \\
\hline First time blood glucose, median (IQR), mmol & $6.98(5.93,8.45)$ & $7.19(6.19,8.27)$ & 0.274 \\
\hline WBC, median (IQR), $\left[\times 10^{9} / \mathrm{L}\right]$ & $12.38 \pm 3.82$ & $12.15 \pm 4.21$ & 0.643 \\
\hline Neutrophil, median (IQR), $\left[\times 10^{9} / \mathrm{L}\right](\mathrm{IQR})$ & $9.24(5.70,11.74)$ & $8.96(5.48,12.28)$ & 0.880 \\
\hline Lymphocyte, median (IQR), $\left[\times 10^{9} / \mathrm{L}\right]$ & $6.70(3.70,10.40)$ & $7.15(4.53,11.50)$ & 0.202 \\
\hline Monocyte, median (IQR), $\left[\times 10^{9} / \mathrm{L}\right]$ & $4.80(2.20,7.65)$ & $5.80(3.80,7.90)$ & 0.085 \\
\hline RBC, median (IQR), $\left[\times 10^{9} / \mathrm{L}\right]$ & $4.29(4.0,4.72)$ & $4.38(3.92,4.74)$ & 0.909 \\
\hline Platelet, median (IQR), $\left[\times 10^{9} / \mathrm{L}\right]$ & $\begin{array}{l}192.0(150.0 \\
234.50)\end{array}$ & $\begin{array}{l}187.50 \\
225.75)\end{array}$ & 0.846 \\
\hline $\mathrm{Hb}$, median (IQR), g/L & $\begin{array}{l}131.0(119.5 \\
141.50)\end{array}$ & $134.0(121.0,145.0)$ & 0.251 \\
\hline Anemia & $21(16.3)$ & $18(14.1)$ & 0.620 \\
\hline $\begin{array}{l}\text { Mechanical ventilation duration, median } \\
\text { (IQR), hours }\end{array}$ & $45.0(33.5,96.0)$ & $48.3(28.26,102.15)$ & 0.609 \\
\hline ICU stay, median (IQR), day & $6.0(4.0,8.0)$ & $6.0(4.0,10.0)$ & 0.040 \\
\hline
\end{tabular}

Values are $\mathrm{n}(\%)$ unless otherwise indicated.

GV = Glucose Variability ;BMI = Body Mass Index; IQR = Interquartile Range; WBC = White Blood Cell; $\mathrm{RBC}=$ Red Blood Cell; $\mathrm{Hb}=$ Hemoglobin. 


\begin{tabular}{|llll|}
\hline Variables & $\begin{array}{l}\text { Lower GV } \\
\text { N=129 }\end{array}$ & $\begin{array}{l}\text { Higher GV } \\
\mathbf{N}=128\end{array}$ & $P$ \\
\hline $\begin{array}{l}\text { Hospitalization days, } \\
\text { median (IQR), day }\end{array}$ & $19.5(14.25,25.0)$ & $20.0(15.0,27.0)$ & 0.455 \\
\hline Values are $\mathrm{n}(\%)$ unless otherwise indicated. & & \\
\hline $\begin{array}{l}\text { GV = Glucose Variability ;BMI = Body Mass Index; IQR = Interquartile Range; WBC = White Blood Cell; } \\
\text { RBC = Red Blood Cell; Hb = Hemoglobin. }\end{array}$ & \\
\hline
\end{tabular}

As shown in Table 3, after adjusting for age, gender, and BMI in model 1, the adjusted hazard ratio (AHR) of WBC was $0.932(P>0.05)$, which was not correlated with the risk of POD; the AHR of APACHE-II > 20 scores was $2.178(95 \% \mathrm{Cl}=1.108-4.281)$, the AHR of hypoxemia was $1.563(95 \% \mathrm{Cl}=1.070-2.518)$, and the AHR of SDBG was $1.436(95 \% \mathrm{Cl}=1.205-1.711)$, all three increased the risk of delirium $(P<0.05)$. In Model 2, the AHR of APACHE-II $>20$ scores was $2.376(95 \% \mathrm{Cl}=1.342-3.876)$, the AHR of hypoxemia was $1.778(95 \% \mathrm{Cl}=1.122-2.818)$, and the AHR of SDBG was $1.418(95 \% \mathrm{Cl}=1.195-1.681)$, all three remained significant after adjusting for confounding factors $(P<0.05)$.

Table 3

Multivariable Cox regression analysis of Possible Predictors of delirium

\begin{tabular}{|c|c|c|c|c|}
\hline & Model 1 & & Model 2 & \\
\hline Variables & $\operatorname{AHR}(95 \% \mathrm{Cls})$ & $P$ & $\mathrm{AHR}(95 \% \mathrm{Cls})$ & $P$ \\
\hline Age, years & $1.007(0.985-1.028)$ & 0.547 & $1.002(0.983-1.002)$ & 0.813 \\
\hline $\mathrm{BMI}, \mathrm{kg} / \mathrm{m}^{2}$ & $1.029(0.971-1.091)$ & 0.336 & $1.021(0.963-1.083)$ & 0.482 \\
\hline Male & $1.381(0.801-2.381)$ & 0.246 & - & - \\
\hline WBC & $0.932(0.852-1.020)$ & 0.124 & $0.993(0.994-1.046)$ & 0.802 \\
\hline First time blood glucose & $1.012(0.968-1.058)$ & 0.607 & $1.015(0.973-1.058)$ & 0.931 \\
\hline Neutrophil & $1.062(0.988-1.143)$ & 0.105 & - & - \\
\hline APACHE-II (> 20 scores) & $2.178(1.108-4.281)$ & 0.024 & $2.376(1.342-3.876)$ & 0.002 \\
\hline Hypoxemia & $1.563(1.070-2.518)$ & 0.046 & $1.778(1.122-2.818)$ & 0.014 \\
\hline SDBG, mmol & $1.436(1.205-1.711)$ & $<0.001$ & $1.418(1.195-1.681)$ & 0.001 \\
\hline Mechanical ventilation duration & $1.000(0.999-1.002)$ & 0.791 & $1.000(0.998-1.001)$ & 0.931 \\
\hline
\end{tabular}


According to the receiver operating characteristic (ROC) curve, the area under curve of the SDBG was $0.763(P<0.01)$. The sensitivity was $81.6 \%$, and the specificity was $57.8 \%$. The area under curve of the MBG was $0.628(P=0.001)$. The sensitivity was $75.7 \%$, and the specificity was $53.2 \%$. The difference of area under the curve between the two groups was statistically significant $(P=0.002)$, which was shown in Fig. 2.

\section{Discussion}

Delirium is a common complication after aortic dissection surgery with the incidence of $32.5-52.0 \%{ }^{4}$ and the results of this study showed that the incidence of delirium was $40.01 \%$, which was consistent with other studies. The area under curve of the SDBG was greater than the MBG. After adjusting for confounding factors, the SDBG were independently correlated with the risk of delirium.

No matter how the quality of perioperative blood glucose controls in patients who undergoing cardiac surgery, blood glucose changes are reported that is related to postoperative complications. ${ }^{20,21}$ After linear regression analysis, the difference between the two groups was statistically significant, which showed that blood GV was a significant predictor of prolonged ICU stay. Multi-factor results showed that blood GV could predict prolonged ICU stay $(O R=1.016, P=0.006)$. Hypoglycemia and hyperglycemia have been identified as risk factors for delirium, ${ }^{22,23}$ but there are few reports on the relationship between glucose fluctuation and delirium. Keulen et al. ${ }^{14}$ shows that delirium is positively associated with hypoglycemia in severe patients with diabetic, but not associated with pronounced glycemic variability. And Heymann et al. ${ }^{24}$ founds that patients with hyperactive delirium have higher MBG than the nonhyperactive delirium patients. There is no consensus on the relationship between glucose fluctuation and delirium,and this study showed that high glycemic variability increases the risk of postoperative delirium.

Glucose, a simple carbohydrate, is the main source of energy for many cells. Studies have shown that the brain consumes $50 \%$ of the total body's consumption of glucose. ${ }^{25}$ In fact, glucose sensory neurons are present in several areas of the brain. The activity of neurons changes with the level of glucose, and the brain function depends on the stable glucose levels, which is why the brain is particularly sensitive to glucose level. Therefore, the blood glucose level needs to be maintained in a narrow physiological range. ${ }^{26} \mathrm{~A}$ study shows that people with diabetes are at least 1.5 times more likely to develop dementia than people without diabetes, further highlighting the effect of glucose changes on the brain function and long-term consequences. ${ }^{25}$ Both acute and chronic hyperglycemia have been shown to cause oxidative stress, subsequent neuronal damage and cognitive decline, ${ }^{27}$ and the reason is closely related to delirium.

At present, the mechanism of blood glucose volatility promoting the development of critical illness and poor prognosis are not clear. However, blood glucose volatility is the biological basis of human body.$^{28}$ According to the theory of oxidative stress, fluctuating hyperglycemia can easily cause oxidative stress than persistent hyperglycemia. ${ }^{29}$ The specific mechanism may be that intermittent hyperglycemia can increase the overexpression of reactive oxygen species in the mitochondrial transport chain, thereby

Page $11 / 18$ 
promoting oxidative stress response, increasing the apoptosis rate of endothelial cells, and ultimately causing damage to central nervous function. ${ }^{27}$ Meanwhile, it has been reported that the oxidative stress of intermittent hyperglycemia is greater than that of sustained hyperglycemia under experimental conditions, which has been confirmed by clinical studies. In addition, high blood glucose will also cause the releasing of a large number of pro-inflammatory cytokines, resulting in coagulation dysfunction, vascular reactivity abnormalities and other injuries. However, patients with acute aortic dissection often present intermittent hyperglycemia due to acute illness, surgical stress, drugs and other reasons, which is closely involved to central nervous injury.

Cardiopulmonary bypass is the main technology for acute aortic dissection.Inflammatory mediators are released in large quantities during cardiopulmonary bypass cardiac surgery, and inflammatory state is another common phenomenon of stress response. The inflammatory response itself has a protective effect on the body. But when the balance between inflammatory and anti-inflammatory is broken, the body shows an inflammatory state and a large number of inflammatory factors in the peripheral circulation enter the central nervous system through various channels, which can cause inflammation in the central nervous system. ${ }^{30} \mathrm{~A}$ large quantity of studies have suggested that neuron inflammation may be one of the mechanisms of cognitive impairment. Cibelli et al. ${ }^{31}$ founds that surgical trauma activates the innate immune system, which in turn triggers an IL-1-mediated inflammatory response in the hippocampus, resulting in memory impairment in mice. In addition, the operation itself is a kind of serious trauma, causing the organism to appear stress state.The imbalance of central nervous system about noradrenaline and acetylcholine decreases the acetylcholine content, resulting in a series of neurological complications.

There are several limitations to this study. First, the sample size was small, and the relevant conclusions need to be further demonstrated with a larger sample. Second, we only evaluated delirium in ICU patients without long-term follow-up. Finally, the number of glucose we measure per day may be less.

\section{Conclusions}

Glucose variability is associated with the risk of delirium in patients after aortic dissection surgery, and high glycemic variability increases the risk of POD. Therefore, we should pay more attention to it.

\section{Abbreviations}

POD

Postoperative delirium

GV

Glucose variability

ICU

Intensive Care Unit

AAD

Page $12 / 18$ 
Acute aortic dissection

MBG

Mean of blood glucose

SDBG

Standard deviation of blood glucose

CAM-ICU

The Confusion Assessment Method for Intensive Care Unit

HR

Hazard ratio

$\mathrm{Cl}$

Confidence intervals

BMI

Body mass index

WBC

White blood cell

APACHE-II

Acute physiology and chronic health evaluation

ROC

Receiver operating characteristic

\section{Declarations}

\section{Ethical approval and consent to participate}

The work was conducted at the Department of Cardiac Surgery, Fujian Medical University Union Hospital. The study was approved by the Ethics Committee of Fujian Medical University Union Hospital(Ethical Review No. 2017KY009). All subjects or their families informed consent form to participate in the study.

Consent for publication Parental/guardian consent obtained.

Availability of data and material The datasets used and analyzed during the current study are available from the corresponding author on reasonable request.

Competing interests No competing interests.

\section{Funding}

This work was supported by grants from the Joint Finds for the innovation of science and Technology, Fujian province (Grant number: 2017Y9052) and Guiding project of science and technology department of Fujian province (Grant number: 2017Y0038).

\section{Authors' contributions}


$\mathrm{L}-\mathrm{YL}$ and $\mathrm{X}-\mathrm{ZH}$ assessed the delirium of the subjects. H-RZ and QC collected socio-demographic and clinical data. Y-CP, L-YL and L-WC analyzed and interpreted the data; Y-JL, L-YL, and H-RZ drafted the manuscript; all authors critically revised the manuscript. All authors read and approved the final manuscript.

\section{Acknowledgements}

The authors thanks the Department of Cardiac Surgery of a tertiary care university hospital and Heart Medicine Research Center.

Authors' Information

\section{Affliations}

${ }^{1}$ Department of Nursing, Fujian Medical University Union Hospital, No.29 Xinquan Road, Fuzhou, Fujian Province, China.

Yan-Juan Lin

${ }^{2}$ Department of Cardiac Surgery, Fujian Medical University Union Hospital, Fuzhou, China.

Yan-Chun Peng\&Liang-wan Chen\&Xi-Zhen Huang

${ }^{3}$ Department of Nursing, Fujian medical University, Fuzhou, China.

Ling-Yu Lin\&Qiong Chen

${ }^{4}$ Department of clinical medicine, Fujian Medical University, Fuzhou, China.

Hao-Ruo Zhang

Correspondence authors Mrs.Yanjuan Lin, fjxhyjl@163.com

\section{References}

1. Abelha FJ, Luís C, Veiga D, et al. Outcome and quality of life in patients with postoperative delirium during. an ICU stay following major surgery. Crit Care. 2013;17:257.

2. Sanson G, Khlopenyuk Y, Milocco S, et al. Delirium after cardiac surgery. Incidence, phenotypes, predisposing and precipitating risk factors, and effects. Heart Lung. 2018;47:408-17.

3. Smulter N, Lingehall HC, Gustafson Y, et al. Delirium after cardiac surgery: incidence and risk factors. Interact Cardiovasc Thorac Surg. 2013;17:790-6.

4. Howard DP, Banerjee A, Fairhead JF, et al. Population-based study of incidence and outcome of acute aortic dissection and premorbid risk factor control: 10-year results from the Oxford Vascular Study. Circulation. 2013;127:2031-7. 
5. Mangusan RF, Hooper V, Denslow SA, et al. Outcomes associated with postoperative delirium after cardiac surgery. Am J Crit Care. 2015;24:156-63.

6. Siddiqi N, Harrison JK, Clegg A, et al. Interventions for preventing delirium in hospitalised non-ICU patients. Cochrane Database Syst Rev. 2016;3:CD005563. doi:.

7. Salluh $\mathrm{Jl}$, Wang H, Schneider EB, et al. Outcome of delirium in critically ill patients: systematic review and meta-analysis. BMJ. 2015;350:h2538. doi:.

8. Pisani MA, Kong SY, Kasl SV, et al. Days of delirium are associated with 1-year mortality in an older intensive care unit population. Am J Respir Crit Care Med. 2009;180:1092-7.

9. Krinsley JS, Maurer P, Holewinski S, et al. Glucose Control, Diabetes Status, and Mortality in Critically III Patients: The Continuum From Intensive Care Unit Admission to Hospital Discharge. Mayo Clin Proc. 2017;92:1019-29.

10. Doola R, Greer RM, Hurford R, et al. Glycaemic variability and its association with enteral and parenteral nutrition in critically ill ventilated patients. Clin Nutr. 2019;38:1707-12.

11. Aramendi I, Burghi G, Manzanares W. Dysglycemia in the critically ill patient: current evidence and future perspectives. Rev Bras Ter Intensiva. 2017;29:364-72.

12. Bansal $B$, Carvalho $P$, Mehta $Y$, et al. Prognostic significance of glycemic variability after cardiac surgery. J Diabetes Compl. 2016;30:613-7.

13. Akirov A, Shochat T, Dotan I, et al. Glycemic variability and mortality in patients hospitalized in general surgery wards. Surgery. 2019;166:184-92.

14. van Keulen K, Knol W, Belitser SV, et al. Glucose variability during delirium in diabetic and nondiabetic intensive care unit patients: A prospective cohort study. PLoS One. 2018;13:e0205637.

15. Lu J, Lu Y, Wang X, et al. Prevalence, awareness, treatment, and control of hypertension in China: data from 1.7 million adults in a population-based screening study (China PEACE Million Persons Project). Lancet. 2017;390(10112):2549-58..Crossref, Medline, Google Scholar.

16. Pape LA, Awais M, Woznicki EM, et al. Presentation, diagnosis, and outcomes of acute aortic dissection: 17-year trends from the International Registry of Acute Aortic Dissection. J Am Coll Cardiol. 2015;66(4):350-8..Crossref, Medline, Google Scholar.

17. Ely EW, Margolin R, Francis J, et al. Evaluation of delirium in critically ill patients: validation of the Confusion Assessment Method for the Intensive Care Unit (CAM-ICU). Crit Care Med. 2001 Jul;29(7):1370-9.

18. Schoe A, Bakhshi-Raiez F, de Keizer N, et al.Mortality prediction by SOFA score in ICU-patients after cardiac surgery; comparison with traditional prognostic-models.BMC Anesthesiol. 2020 Mar 13;20(1):65.

19. Li Y, Yuan D, Li X, Wang S.Risk factors for delirium in intensive care unit and its duration.Zhonghua Wei Zhong Bing Ji Jiu Yi Xue. 2020 Jan;32(1):62-66.

20. Ogawa S, Okawa $Y$, Sawada $K$, et al. Continuous postoperative insulin infusion reduces deep sternal wound infection in patients with diabetes undergoing coronary artery bypass grafting using bilateral 
internal mammary artery grafts: a propensity-matched analysis. Eur $\mathrm{J}$ Cardiothorac Surg. 2016;49:420-6.

21. Subramaniam B, Lerner A, Novack V, et al. Increased glycemic variability in patients with elevated preoperative $\mathrm{HbA} 1 \mathrm{C}$ predicts adverse outcomes following coronary artery bypass grafting surgery. Anesth Analg. 2014;118:277-87.

22. Zaal I, Devlin J, Peelen L, et al. A systematic review of risk factors for delirium in the ICU. Crit Care Med. 2015;43:40-7.

23. Inouye S, Westendorp RGJ, Saczynski J. Delirium in elderly people. Lancet. 2014;383:911-22.

24. Hyperactive delirium and blood glucose control Heymann A, Sander M, Krahne D, et al. Hyperactive delirium and blood glucose control in critically ill patients. J Int Med Res. 2007;35:666-77.

25. Scheen AJ. Central nervous system: a conductor orchestrating metabolic regulations harmed by both hyperglycaemia and hypoglycaemia. Diabetes Metab. 2010;36:31-8.

26. Sanford AM, Flaherty JH. Do nutrients play a role in delirium? Curr Opin Clin Nutr Metab Care. 2014;17:45-50.

27. Stadler K. Oxidative stress in diabetes. Adv Exp Med Biol. 2012;771:272-87.

28. Silverstein JH, Steinmetz J, Reichenberg A, et al. Postoperative cognitive dysfunction in patients with preoperative cognitive impairment: which domains are most vulnerable? Anesthesiology. 2007;106:431-5.

29. Newman MF, Kirchner JL, Phillips-Bute B, et al. Longitudinal assessment of neurocognitive function after coronary-artery bypass surgery. N Engl J Med. 2001;344:395-402.

30. Cunningham C, Campion S, Lunnon K, et al. Systemic inflammation induces acute behavioral and cognitive changes and accelerates neurodegenerative disease. Biol Psychiatry. 2009;65:304-12.

31. Cibelli M, Fidalgo AR, Terrando N, et al. Role of interleukin-1 beta in postoperative cosnitive dysfunction. Ann Neurol. 2010;68:360-8.

\section{Figures}




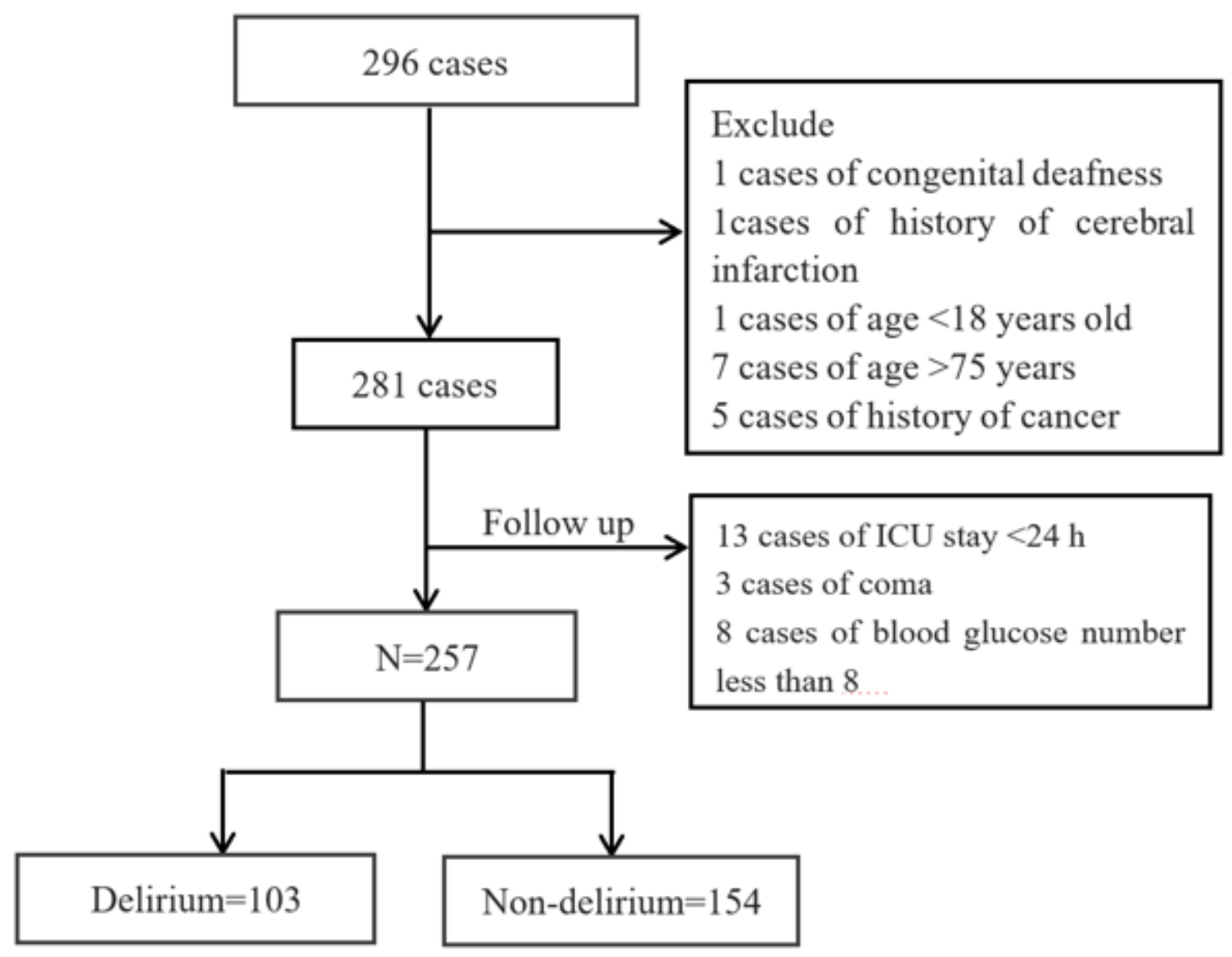

Figure 1

Flowchart of the study. From June 2017 to June 2019, 296 patients with AAD were included, and 257 patients were finally included. There were 103 patients with delirium and 154 patients with non-delirium. 


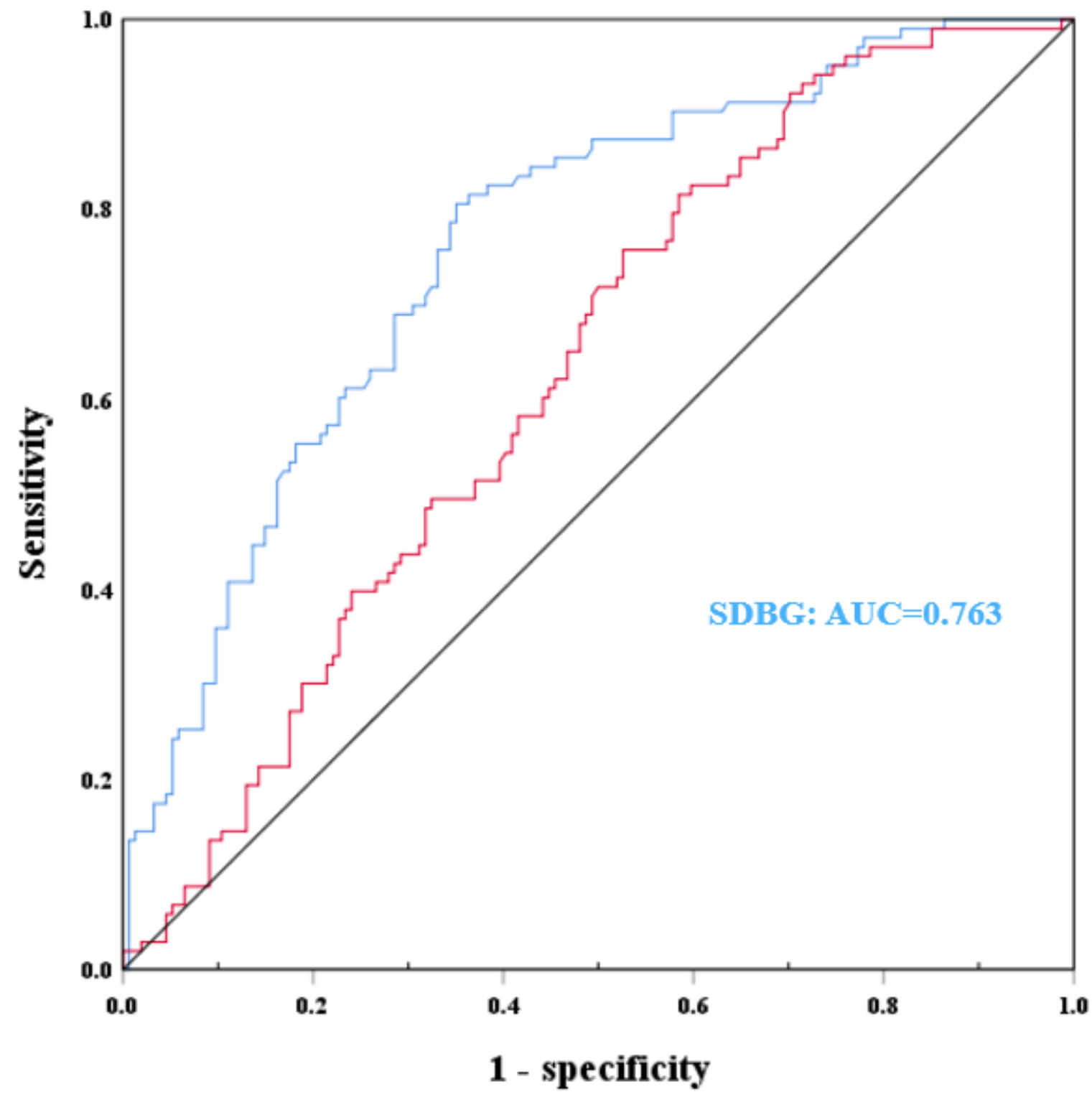

Figure 2

The ROC curves of predict POD of patients with AAD. The area under curve of the SDBG was $0.763(\mathrm{P}<$ $0.01)$. The sensitivity was $81.6 \%$, and the specificity was $57.8 \%$. The area under curve of the MBG was $0.628(P=0.001)$. The sensitivity was $75.7 \%$, and the specificity was $53.2 \%$. 